\title{
Auditory detection of narrow-band noise and tonal signals'
}

\author{
P. T. CORNELIUS, J. K. WHITMORE ${ }^{2}$ AND W. A. WILBANKS \\ UNIVERSITY OF MISSISSIPPI
}

The detectability of narrow-band noise and tonal signals is shown to be a function of the interaural correlation of the masking noise. The same amount of binaural release from masking is obtained with both signals. This finding is interpreted in terms of signal detection theory.

In the approach to signal detection taken by Peterson, Birdsall, \& Fox (1954) and by Jeffress (1964, 1967), the basis for detection is some transformation of the noise distribution resulting from the addition of the signal. Since signal plus noise is qualitatively no different from noise, it makes no difference whether the signal itself is one frequency or many, i.e., a sinusoid or narrow-band noise. This study compares detection of sinusoidal and narrow-band noise signals as a function of the interaural correlation of the masking noise.

\section{Experiment 1}

The signal, a $250 \mathrm{~Hz}$ pure tone, was presented monaurally at the listener's more sensitive ear. The duration of the signal (200 $\mathrm{msec}$ ) was controlled by an Iconix electronic counter that triggered a GrasonStadler switch, gating the signal with a $25 \mathrm{msec}$ rise-fall time. The signal was partially masked by continuous $250 \mathrm{~Hz}$ narrow-band noise centered at $250 \mathrm{~Hz}$. Detection was studied with a monaural noise and under six interaural noise correlations: +1.00 , $+.90,+.75,+.50,+.25$, and 0 . These correlations were obtained by mixing the outputs of three noise generators. 3 The spectral level of the noise for all conditions was approximately $33 \mathrm{~dB}$ re $0.0002 \mathrm{mi}-$ crobar.

Masked thresholds, defined as the signal level in $\mathrm{dB}$ for $d_{s}=1.50$, were obtained on two experienced Ss by means of the fixed-interval observation experiment (FIOE) as described by Egan, Greenberg, \& Schulman (1961). The listeners used a five-category rating scale to indicate the likeness of the momentary input to the noise. The rating-scale data yielded receiver operating characteristic (ROC) curves, from which measures of detection, $d_{s}$, were obtained. Threshold signal levels were determined by the method described by Jeffress (1964), and by Wilbanks \& Whitmore (1967). 4

\section{Experiment 2}

The signal, a $135 \mathrm{~Hz}$ narrow-band noise centered at $250 \mathrm{~Hz}$, was presented at the listener's more sensitive ear. The duration of the signal (150 msec) was controlled by an Iconix electronic counter that triggered a Grason-Stadler switch, gating the signal with a $10 \mathrm{msec}$ rise-fall time. The signal was par- tially masked by continuous wide-band noise, cut off at the lower end by the response of the earphones (TDH-49) and at the upper end by a $3000 \mathrm{~Hz}$ low-pass passive filter. Two noise generators were used to obtain noise correlations of $+1.00,+.95,+.87,+.71$, $+.50,+.22$, and 0.5 Detection was also studied with both signal and masker presented monaurally. The spectral level of the masker for all conditions was approximately $45 \mathrm{~dB}$.

Masked thresholds were obtained on five experienced Ss by means of a two-alternative, temporal forced-choice (2AFC) method. Average percent correct choices for each condition were converted to $d^{\prime}$ (Blosser, 1965), and the signal level in $\mathrm{dB}$ for $d^{\prime}=1.50$ was determined by the method used in Experiment 1.6

\section{Results and Discussion}

The results are shown in Fig. 1. Here the ordinate is masking level difference (MLD) in $\mathrm{dB}$, the abscissa is the interaural correlation of the masker, and the parameter is signal class (sinusoid or narrow-band noise). The size of the MLD indicates the amount by which the level of the signal must be reduced (binaural release from masking) or increased to maintain the same detection score $\left(d^{\prime}=1.50\right)$ for each interaural condition with respect to the monaural. Figure 1 shows that as the correlation of the masker is increased to unity, the advantage of binaural over monaural detection increases. By adding correlated noise at the non-signal ear, the human observer achieves an improvement in signal-to-noise ratio of about 10-11 dB. These results are consistent with those of other investigators (e.g., Robinson \& Jeffress, 1963; Langford \& Jeffress, 1964; Wilbanks \& Whitmore, 1967).

The finding of interest here is that the data for a narrow-band noise signal centered at $250 \mathrm{~Hz}$ and the data for a $250 \mathrm{~Hz}$ sinusoid can be adequately described by a single curve. In a study using tonal signals, Wilbanks \& Whitmore (1967) found that the relationship between MLD and interaural noise correlation can be described rather accurately by the equation: $M L D=20 \log \left(1-\mathrm{kr}^{2}\right)^{-1 / 2}$, where $k$ is an attenuation or proportionality constant, and $r$ is the coefficient of interaural correlation for noise. The smooth curve in Fig. 1 is based upon this equation. 7 It should be noted that the MLDs for narrow-band noise signal tend to be about $1 \mathrm{~dB}$ larger than those for the sinusoidal signal. This difference can be attributed to the differences in the levels of the maskers and signal durations employed in the two 


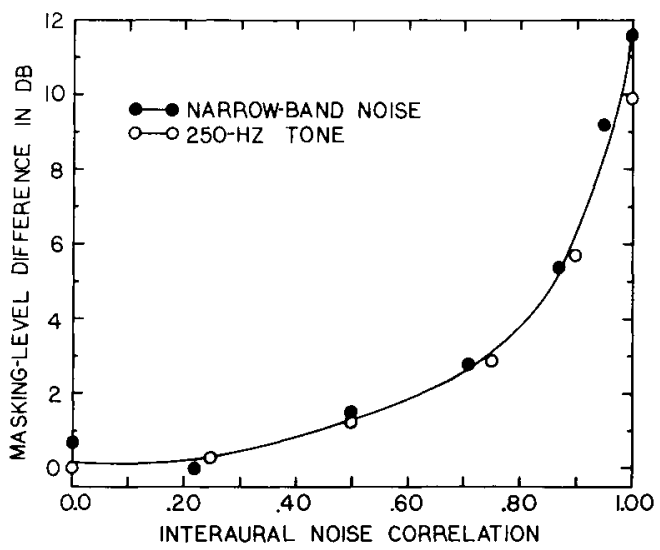

Fig. 1. Masking-level differences for narrow-band noise and sinusoidal signals as a function of masker correlation.

experiments. Rilling \& Jeffress (1965) and Webster (1951) also report that sinusoidal and narrow-band noise signals yield comparable MLDs under similar interaural conditions.

As stated earlier, detection theory views the basis of detection as some sort of transformation of the noise distribution resulting from the addition of the signal. In other words, the signal plus noise distribution is not viewed as differing qualitatively from the noise alone distribution. The present results are in agreement with this view in showing that it makes no difference to the detection mechanism whether the "signal" is a single frequency or many. What is detected is some change in the noise.

\section{References}

BLOSSER, ANN B. A performance-oriented approach to detection: Tables for detection, discrimination, and decision theory. Tracor, Inc. 1965 , Doc. No. 65-267-U.

EGAN, J. P., GREENBERG, G. Z., \& SCHULMAN, A. I. Interval of time uncertainty in auditory detection. J. Acoust. Soc. Amer., 1961, 33, 771-778.

JEFFRESS, L. A. Stimulus-oriented approach to detection. J. Acoust. Soc. Amer., 1964, 36, 766-774.

JEFFRESS, L. A. Stimulus-oriented approach to detection re-examined. J. Acoust. Soc. Amer., 1967, 41, 480-488.

JEFFRESS, L. A., \& ROBINSON, D. E. Formulas for the coefficient of interaural correlation for noise. J. Acoust. Soc. Amer., 1952 $34,1658(\mathrm{~L})$.

LANGFORD, T. L., \& JEFFRESS, L. A. Effect of noise crosscorrelation on binaural signal detection. J. Acoust. Soc. Amer., $1964,36,1455-1458$.

LICKLIDER, J. C. R., \& DZENDOLET, E. Oscillographic scatterplots illustrating various degrees of correlation. Science, 1948, 107, 121-124.

MARILL, T. Detection theory and psychophysics. Mass. Inst. Technol. Res. Lab. Electron., 1956, Rept. No. 319.

PETERSON, W. A., BIRDSALL, T. G., \& FOX, W. C. The theory of signal detectability. Trans. IRE, 1954, PGIT-4, 171-212.

RILLING, M. E., \& JEFFRESS, L. A. Narrow-band noise and tones as signals in binaural detection. $J$. Acoust. Soc. Amer., 1965, 38, 202-206.

ROBINSON, D. E., \& JEFFRESS, L. A. Effect of varying the interaural noise correlation on the detectability of tonal signals. $J$. Acoust. Soc. Amer., 1963, 35, 1947-1952.

WEBSTER, F. A. Influence of interaural phase on masked thresholds. J. Acoust. Soc. Amer., 1951, 12, 452-462.

WHITMORE, J. K., \& WILBANKS, W. A. Interaural noise correlation and detection of low-frequency signals. J. Acoust. Soc. Amer., 1965, 38, 929(A).

WILBANKS, W. A. Detection of a narrow-band noise as a function of the interaural correlation of both signal and masker. J. A coust. Soc. Amer., 1967, 41, 1612(A).

WILBANKS, W. A., \& WHITMORE, J. K. Detection of monaural signals as a function of interaural noise-correlation and signal frequency. J. Acoust. Soc. Amer., 1967, in press.

Notes

This work was supported by Grant No. MH-14039-01, U. S. Public Health Service, National Institute of Mental Health. The theoretical psychometric functions used to determine masked thresholds were prepared by Dr. Whitmore, Paul Williams and Harold Ermey of the University of Texas.

1. The results of this study were presented to the 70th and the 73rd Meetings of the Acoust. Soc. Amer. (J. Acoust. Soc. Amer., 1965, 38, 929(A); J. Acoust. Soc. Amer., 1967, 41, 1612(A)). 2. Currently, a National Institute of Mental Health Post-doctoral Research Fellow to the Department of Psychology, University of Texas.

3. This way of varying interaural noise correlation has been thoroughly discussed by Licklider and Dzendolet (1948), and by Jeffress and Robinson (1962) who show that it involves reducing the correlation by introducing error variance at the two ears, as in a product-moment correlation.

4. The theoretical psychometric function used is based on Marill's (1956) expression for the Rayleigh-Rice distribution for narrow-band noise and narrow-band noise plus sinusoidal signal, $P(C)=1-1 / 2 e^{-E / N o}$. On the basis of this curve, the signal level in $\mathrm{dB}$ required to yield $\mathrm{d}_{\mathrm{s}}=1.50$ may be inferred from an obtained $\mathrm{d}_{\mathrm{s}}$ and the signal level associated with it.

5. Here the interaural correlation for noise is reduced by decreasing the amount of noise variance common to both ears, as in an analysis of variance approach.

6. The theoretical psychometric function used to determine these "threshold" signal levels is here based on the Rayleigh-Rayleigh distribution for a narrow-band noise signal and a narrow-band ("critical band") masker, $\mathrm{P}(\mathrm{C})=\left(1+\sigma_{\mathrm{s}}{ }^{2}\right) /\left(2+\sigma_{\mathrm{s}}^{2}\right)$ where $\sigma_{\mathrm{s}}$ is the signal voltage and the noise voltage is unity.

7. A theoretical paper by Whitmore showing the derivation of this equation is in preparation. It is used here in its descriptive sense. 